\title{
Improvement in Geotechnical Properties of Expansive Soil Using Various Stabilizers: A Review
}

\author{
Goutham D.R. \\ Department of Civil Engineering, Adichunchanagiri Institute of Technology, Chikkamagaluru-577102, India \\ E-mail: goutham.dr03@gmail.com \\ A.J.Krishnaiah \\ Department of Civil Engineering, Malnad College of Engineering, Hassan-573202, India
}

Received: 13 July 2020; Accepted: 07 September 2020; Published: 08 October 2020

\begin{abstract}
Expansive soils are the soils that expand when comes in contact with water and shrinks when the water within them gets evaporates. These soil are treated as problematic soils for various construction activities hence there is an essential to improve its strength against load effects and also to alter their behaviour against moisture conditions. This review aimed to study the behaviour of expansive soil stabilized using various natural and industrial processed materials such as cement, polymer, lime, rice husk ash, stone dust, fly ash, coir fiber and its pith, jute, bagasse ash and ground granulated blast furnace slag (GGBS). The paper covers the discussion on experimental test results of black cotton soil conducted by various researchers. The tests being basic geotechnical properties, maximum dry density and optimum moisture content, unconfined compressive strength test (UCS), California bearing ratio (CBR), etc., are presented.
\end{abstract}

Index Terms: Expansive soil, stabilization, basic geotechnical properties, unconfined compressive strength test.

\section{Introduction}

Expansive soils behave in a different way from other normal soils due to their affinity to swell and shrink. The swelling potential of a soil basically depends upon its mineral composition alongside with the in situ moisture content and density. Soil porousness also affects the rate of swelling on site. Normally clays with plasticity indices $>25$, liquid limits $>40$, and natural water content near the plastic limit or less are more expected to swell. Soils containing coarsegrained particles, i.e. cobbles, pebbles, and sands, possibly will also be expansive depending upon the percentage and type of clay minerals present in its fine content. Clays fundamentally belong to the family of silicates minerals and their chief elements are silicone, aluminium, and oxygen. However, many elements can merge into the clay mineral structure, such as hydrogen, sodium, calcium, magnesium, sulphur, etc. Some of the clay minerals showing swelling behaviour include smectite, bentonite, montmorillonite, beidellite, vermiculite, attapulgite, nontronite, and chlorite [14].

Black cotton soil is one of the prime soil deposits in India. Black cotton soil features a high percentage of clay, which is primarily montmorillonite in structure and black or blackish-grey in color [2]. It is largely found in southern, western, and central parts of India, covering Andhra Pradesh, Karnataka, Gujarat and some parts of Madhya Pradesh [4]. Due to its swell and shrinkage behaviour, black cotton soil is considered as problematic soil for highway construction, high rise structures, the foundation of any major hydraulic structures and airfield pavements. Alternative wetting and drying of black cotton soil cause vertical movement resulting in failure of structures that are built over them. Replacing the existing soil might not be a feasible option therefore; the best available approach is to stabilize the soil with suitable stabilizers [5]. This review will demonstrate various stabilizers used by researchers to treat black cotton soil and its effects caused to the soil.

Ikeagwuani et al., [18] have studied the emerging trends in expansive soil stabilization. They have concentrated on the characteristics of expansive soil, soil stabilization techniques, engineering properties of stabilized soils using different techniques, and more emphasis is given to microstructural interaction analysis. Some of the stabilizers used in this study are GGBS, precipitated silica, micro-fine slag, waste paper sludge ash, calcium carbide residue, burned sewage sludge, rice husk ash, locust bean waste ash, sawdust ash, bagasse ash, shell powder, and crumb rubber particles are presented with their optimum content and found some crucial findings. They have also addressed the current issues in stabilization practices such as standardization issues, geoenvironmental issues, and optimization issues. Afrin [19] has studied a review on different types of stabilization techniques. She has focused on soil stabilization methods such as lime stabilization, cement stabilization, chemical stabilization, fly ash stabilization, rice husk ash stabilization, bituminous stabilization, 
thermal stabilization, electrical stabilization, and stabilization by geotextile and fabrics. Also, the work is stretched to understand the factors affecting the strength of stabilized soil such as organic matter, sulphates, sulphides, compaction, moisture content, temperature, and freeze-thaw and dry-wet effects. Khajeh et al., [20] they have studied the fundamental soil-cement stabilization practice. Four types of cemented soil study are carried out; they are cement-stabilized clays, cement-stabilized sands, cemented soils, and reinforced cemented composites. The effect of cement on sample preparation, compaction, splitting tensile strength, unconfined compressive strength, cohesion, internal friction angle, Young's and shear moduli, and failure envelope are presented in the forms of summary for cement-stabilized clays and cementstabilized sands. Cemented soil in addition to various other products such as fly ash, granulated blast furnace slag (GBFS), silica, metakaolin, and rice hush ash are considered to understand their behaviour with cemented soil. Reinforced cemented composites with expanded polystyrene material (EPS), polypropylene fibers (PP), glass fibers, polyvinyl alcohol fibers (PVA,) and nylon fibers are taken for comparative study.

\section{$1.1 \quad$ Problems connected with expansive soils}

$>$ Severe damage to the foundation, structural components of the buildings, roads, and water retaining structures due to the differential movements of the soil during variation in atmospheric conditions.

$>$ It aids in additional lateral pressure at the foundation wall because of increasing moisture content adjacent to the foundation wall.

$>$ Instability of slopes posing sliding problems.

$>$ Leakage problems at the basement of the building.

Therefore, to overcome these problems, soil stabilization is a preferred technique to significantly make expansive soil more resistant against the above said effects before taking up any construction activity.

\subsection{Soil Stabilization}

The process of improving the shear strength parameters of soil is called soil stabilization. Soil stabilization is an effective method of improving soil properties by blending and mixing other materials. Some soils possess low bearing capacity thus stabilization technique aims to improve the bearing capacity of the soil as it is required when the soil available for construction is not at all appropriate to withstand structural load. The stabilization can be carried out in two broad ways; mechanical stabilization and chemical stabilization. The soil gradation is altered in the mechanical stabilization process whereas in chemical stabilization; chemicals are used to modify soil properties.

\subsection{Objectives of the review}

$>$ To highlight the basic index properties of expansive soil.

$>$ To focus on the effect of stabilizers in the behaviour of expansive soil.

$>$ To recognize the optimum dose of stabilizers used in the expansive soil.

\section{Types of Stabilizers}

\section{$2.1 \quad$ Cement and polymer stabilizer}

Cement base pavement has an advantage of great strength and durability. Also, it is widely available hence becomes the best material for stabilization of soil. The hydrated product of cement binds with soil to form the cement-stabilized base or cement treated aggregate base [11]. Polymer is simply a long chain of monomers which is connected to each other by a sufficiently strong and flexible van der Waals force. The polymer stabilizer creates polymer coating around the soil particle which eventually connects soil particles with each other by a flexible bond [1]. A study has been carried out to find a solution to the problems related to black cotton soil by conducting a detailed laboratory investigation on the soil sample which was stabilized with cement and polymer stabilizer. The black cotton soil was procured from Madhya Pradesh, the area which is predominant with black cotton soil. The black cotton soil used for the present study belongs to $\mathrm{CH}$ classification. The polymer stabilizer called 'Renolith' is used along with cement (Portland pozzolana cement) to improve its efficiency with the soil particles. Cement is varied from $2 \%$ to $8 \%$ at a regular interval of $2 \%$ to the weight of the soil and the polymer stabilizer is used in the range of $0 \%$ to $8 \%$ at an interval of $2 \%$ to the weight of the cement. The geotechnical properties of the stabilized soil such as liquid limit, plasticity index, differential free swell, unconfined compressive strength test (UCS), California bearing ratio (CBR), and scanning electron microscope (SEM) were studied for different mix proportions of cement and polymer stabilizer. An increase in the percentage of polymer stabilizer by the weight of cement for all percentage of cement added shown a gradual decrease for liquid limit values. The liquid limit test was conducted after 24 hours of mixing the stabilizer into the soil sample. For $2 \%$ of cement added, the liquid limit value is $54 \%$ at $0 \%$ polymer stabilizer and this value decreases to $47 \%$ at $8 \%$ of polymer stabilizer. Similarly, for $8 \%$ of cement added, the liquid limit value is $39.3 \%$ at $0 \%$ polymer stabilizer and this value decreases to $36 \%$ at $8 \%$ of polymer stabilizer. 
This reveals that an increase in the percentage of polymer stabilizer by the weight of cement for all percentage of cement added to the soil had shown a declined trend for liquid limit values. For $2 \%$ of cement added, the plasticity index value is $23.4 \%$ at $0 \%$ polymer stabilizer and this value reduces to $17 \%$ at $8 \%$ of polymer stabilizer. Similarly, for $8 \%$ of cement added the plasticity index value is $10.1 \%$ at $0 \%$ polymer stabilizer and this value decreases to $7.45 \%$ at $8 \%$ of polymer stabilizer. This shows that there is a significant decrease in plasticity index value when the polymer stabilizer is used on a higher percentage with the cement. The consequence of stabilized black cotton soil during differential free swell index is also compromising that the usage of polymer stabilizers with cement on a higher percentage concluded a decrease in the values. CBR test was conducted on soaked unstabilized soil and the result for $2.5 \mathrm{~mm}$ penetration was $2.63 \%$. The soaked CBR values for 1 day of curing had shown an increase in the CBR values when polymer content to cement is increased. For $2 \%$ of cement added, the CBR is $4.52 \%$ at $0 \%$ polymer stabilizer and this value got increased to $8.4 \%$ at $8 \%$ of polymer stabilizer. Similarly, for $8 \%$ of cement added the CBR is $12.21 \%$ at $0 \%$ polymer stabilizer and this value increases to $22.4 \%$ at $8 \%$ of polymer stabilizer. UCS test was carried out on the soil sample with optimum moisture content obtained during the compaction test. The soil specimen was compacted with heavy compaction and they are kept for curing for 1 day and 7 days. The UCS values for unstabilized black cotton soil works out to be $612 \mathrm{kN} / \mathrm{m}^{2}$. For $2 \%$ of cement added, the UCS value is $708 \mathrm{kN} / \mathrm{m}^{2}$ at $0 \%$ polymer stabilizer and this value increases to $1480 \mathrm{kN} / \mathrm{m}^{2}$ at $8 \%$ of polymer stabilizer. Similarly, for $8 \%$ of cement added, the UCS value is $1211 \mathrm{kN} / \mathrm{m}^{2}$ at $0 \%$ polymer stabilizer and this value increases to 1825 $\mathrm{kN} / \mathrm{m}^{2}$ at $8 \%$ of polymer stabilizer. The scenario on UCS values reported the same when it is compared to the CBR value. Higher the amount of cement and polymer stabilizer used higher the UCS values. The UCS values for 7 days soaked soil specimen had shown the same kind of behaviour that to the 1 day soaked soil specimen [1].

\subsubsection{Findings}

Scanning electron microscopy images reveal the formation of polymer coating around soil particles. This polymer coating will retard the water absorption capacity of the soil reducing swell and shrink potential. The curing period of the soil sample can be further amplified to check the long term effect of soil stabilizer. The optimum dose of cement and polymer is $8 \%$.

\subsubsection{Summary}

Results have shown that the utilization of cement and polymer in the expansive soil had modified the shear strength parameters of the soil also there are alterations in the basic index property of the soil.

\subsection{Lime}

A study has been carried out to know the behavior of black cotton soil stabilized with lime. The black cotton soil was procured from Latur, Maharashtra which showed low to medium swelling potential. The hydrated lime gets reacts with clay minerals present in the black cotton soil and they undergo to stiff cementitious matrix. There are some benefits of using lime as a stabilizing agent that improves the shear strength of the soil and it also enhances the volume stability of the soil. Geotechnical properties of soil such as Atterberg's limits, standard proctor test, differential free swell test (DFS), swelling pressure test, and California bearing ratio test (CBR) are conducted by using lime content. Lime is varied from $2.5 \%$ to $7.5 \%$ at an interval of $0.5 \%$ to the weight of the soil. The liquid limit of untreated soil was $59.8 \%$ and it changes to $53.2 \%$ to $59.5 \%$ with the addition of lime content. From the test, it is evident that for $4.5 \%$ of lime content, the liquid limit value tends to be lesser and beyond this point liquid limit value starts to increase. Hence $4 \%$ to $4.5 \%$ of lime content is considered as optimum dosage. The plastic limit of untreated soil was $33 \%$ and it changes to $32 \%$ to $40 \%$ with the addition of lime content. There are no much changes in the plastic limit values for stabilized soil, but the lowest value of the plastic limit was reported as $32 \%$ for $4 \%$ of lime added. The plasticity index value decreases with an increase in the lime content. For untreated black cotton soil, the plasticity index was 26\% and it decreases to $16 \%$ at $7.5 \%$ of lime content. Considering into the account of Atterberg's limit and grain sieve analysis, the soil has been classified as $\mathrm{MH}$. Based on standard compaction test results, the maximum dry density of the soil remains constant irrespective of lime content added but the optimum moisture content lies in between $23 \%$ to $30 \%$ in declining trend with an increase in lime content hence there is no appreciable increase in the dry density of the soil. The OMC reported for $2.5 \%$ of lime content was $25 \%$ and it reaches the maximum value of $30 \%$ at $3.5 \%$ dose of lime content. Further, the OMC had attained declination to $19 \%$ at $7.5 \%$ of lime content. Very interestingly, the differential free swell values decrease with an increase in the lime content. For virgin soil the DFS value reported was 39\% and it changes to $34 \%$ at $2.5 \%$ of lime added, further it gradually decreases to $27 \%$ at $7.5 \%$ of lime content. The swelling pressure test on black cotton soil marked the value of $1.06 \mathrm{~kg} / \mathrm{cm}^{2}$. At $2.5 \%$ of lime content, the swelling pressure value decreases to 0.42 $\mathrm{kg} / \mathrm{cm}^{2}$ and the value tends to decrease up to $3.5 \%$ of lime content thereafter it again increases to $0.6 \mathrm{~kg} / \mathrm{cm}^{2}$ at $7.5 \%$ of lime content. The consequences of CBR values are the same as that of the swelling pressure test. The CBR value reported was $11 \%$ at $2.5 \%$ of lime and it decreases to $6 \%$ at $3.5 \%$ of lime. Further, the behaviour gradually starts to increase upon the addition of lime content. The maximum CBR value reported was $18 \%$ at $5 \%$ of lime content [2]. 


\subsubsection{Findings}

The optimum lime content to be used in the soil is in the range of 3.5\% to 4.5\%. It is also observed that the stiffness of the soil had increased as the lime content is increased in the soil.

\subsubsection{Summary}

Utilization of lime to stabilize the soil is an effective method to overcome swell and shrinkage problems in the expansive soil. Lime stabilization has some benefits to the soil such as enhanced workability, higher strength, and bulk stability.

\subsection{Rice husk ash and lime}

Pozzolanas are siliceous and/or aluminous materials, which in themselves possess minute or no cementing properties, but chemically react with calcium hydroxide, such as lime, to form compounds possessing cementitious properties. The rice husk ash contains around $90 \%$ of silica which is the maximum concentration of all plant residues [12]. A work is undertaken to study on engineering properties of black cotton soil which is stabilized using rice husk ash (RHA) and lime with randomly distributed polypropylene fiber (PPF). RHA and lime have much advantage part in soil stabilization and it is also used extensively for stabilization of foundation soil and road subgrade. The expansive soil used in this study was procured from Bhubaneswar. RHA was obtained from the parboiling plant at Orissa and commercially available quick lime was used. PPF of $12 \mathrm{~mm}$ length is utilized. The soil engineering properties such as maximum dry density (MDD), optimum moisture content (OMC), unconfined compressive strength (UCS), splitting tensile strength, soaked California bearing ratio (CBR), swelling pressure and durability tests are conducted. The untreated black cotton soil belongs to CH classification and its liquid limit is $60 \%$. The plastic limit and plasticity index of origin soil is $32 \%$ and $28 \%$. The amount of RHA is varied from $5 \%$ to $20 \%$ to the dry weight of the soil at an interval of $5 \%$ and lime content is varied from $2 \%$ to $5 \%$ by the dry weight of the soil at an interval of $1 \%$. PPF was added from $0.5 \%$ to $2 \%$ at an increment of $0.5 \%$. To find the optimum dose of RHA and lime, the soil samples are prepared with different proportions of RHA and lime and are cured for 0,7 days and 28 days and UCS test is performed. After the UCS test, the optimum dose of RHA is reported as $10 \%$ to the dry weight of the soil and the optimum dose of lime is marked as $4 \%$ to the dry weight of the soil. The untreated black cotton soil bears the maximum dry density value of $16.1 \mathrm{kN} / \mathrm{m}^{3}$ with optimum moisture content of $21 \%$. When the optimum percentage of RHA and lime is mixed to the black cotton soil at $0.5 \%$ of PPF, the MDD value decreases to $14 \mathrm{kN} / \mathrm{m}^{3}$ and OMC increases to $25.8 \%$, the test results had reported that irrespective of the increase in PPF will lead to the decrease in MDD values and increase in the OMC values. The soil samples are prepared and kept in a humidity chamber for above mentioned days and UCS test, splitting tensile test, soaked CBR test, swelling pressure test and durability test were carried out. The untreated black cotton soil had the UCS value of $60 \mathrm{kN} / \mathrm{m}^{2}$ and this value got increased to $68 \mathrm{kN} / \mathrm{m}^{2}$ when the soil is added with the optimum percentage of RHA and lime. With the addition of $1.5 \%$ of PPF, the UCS values kept increasing irrespective of curing periods. Beyond $1.5 \%$ of PPF there is a considerable decrease in UCS values for all curing periods. The UCS value increased to $571 \mathrm{kN} / \mathrm{m}^{2}$ at 28 days of curing. However, there is no greater improvement in the UCS values beyond $1.5 \%$ of fiber added to the soil. The splitting tensile strength of virgin black cotton soil was $20 \mathrm{kN} / \mathrm{m}^{2}$ and it decreases to $15 \mathrm{kN} / \mathrm{m}^{2}$ when soil is stabilized with the optimum percentage of RHA and lime. The splitting tensile strength kept increasing with an increase in fiber content up to $1.5 \%$ and thereafter it declines. Irrespective of the curing period, the splitting tensile strength increased only to $1.5 \%$ of fiber content. The maximum splitting strength value reported for 28 days curing period is $78 \mathrm{kN} / \mathrm{m}^{2}$. The soaked CBR value of untreated black cotton soil was $1.98 \%$ and it is increased to $2.94 \%$ when the soil is added with the optimum dose of RHA and lime. It is observed in the CBR value that up to $1.5 \%$ of PPF with optimum dose of RHA and lime, the values kept ascending irrespective of curing periods. For 28 days of curing period the CBR value reported as $19.1 \%$. The swelling pressure of virgin black cotton soil was $138 \mathrm{kN} / \mathrm{m}^{2}$ and shockingly it has got decreased to $54 \mathrm{kN} / \mathrm{m}^{2}$ when the soil is mixed with optimum dose of RHA and lime. From the test, it is evident that the swelling pressure of soil at $2 \%$ of fiber content with the optimum dose for 28 days of curing period reported the value of $4 \mathrm{kN} / \mathrm{m}^{2}$. It is observed that for all the curing periods irrespective of fiber content the swelling pressure values tend to decrease. Durability tests reveal the clear picture of stabilizer used and fiber used in treating black cotton soil. The investigation had shown that the RHA and lime used did not affect the strength characteristics of the soil also the PPF used did not make its impression on reduction in load-carrying capacity of the soil [3].

\subsubsection{Findings}

Due to the addition of polypropylene fiber (PPF), maximum dry density has reduced and optimum moisture content kept increasing which is considered to be a drawback. Polypropylene fiber of $1.5 \%$ and rice hush ash of $10 \%$ is suitable to use in the expansive soil. 


\subsubsection{Summary}

The use of rice husk ash as a stabilizer will increase the load-carrying capacity of the expansive soil also it will eliminate the problem of disposal of this waste which is abundantly available in the environment.

\subsection{Stone dust and lime}

The suitability of stone dust and lime in the black cotton soil is studied. Lime used for soil treatment is high calcium lime, which contains not more than 5\% of magnesium oxide or hydroxide [4]. The black cotton soil is procured from Gwalior-Jhansi road, BSF area (NH: 7), Gwalior. Stone dust is procured from the stone crusher plant of Aman Vihar Industrial Area, New Delhi, and locally available lime is used. Initially, the lime is mixed in different percentages ranging from $3 \%$ to $12 \%$ to the black cotton soil and a standard compaction test is performed to fix the optimum dosage of lime content for the soil. Based on the test results, the optimum dosage of lime is obtained as $9 \%$ to the dry weight of the soil. The stone dust is utilized in the range of 0 to $25 \%$ to the dry weight of the soil at an increment of $5 \%$. Three strength parameters are studied with different mix combination of stone dust to the black cotton soil keeping lime as constant. The strength parameters are maximum dry density (MDD), California bearing ratio (CBR), and unconfined compression test (UCS). The morphological behaviour of the soil is also studied by introducing a scanning electron microscopy test. According to the test results, the untreated black cotton soil belongs to $\mathrm{CH}$ classification with a liquid limit of $57 \%$, plastic limit $31.4 \%$, and a plasticity index of $26.5 \%$. Light compaction technique is used to find the maximum dry density of origin soil and it is $16.1 \mathrm{kN} / \mathrm{m}^{3}$, due to the addition of $9 \%$ lime content to the black cotton soil the MDD value reaches to maximum of $16.6 \mathrm{kN} / \mathrm{m}^{3}$ and later it starts to decrease. By keeping the optimum dose of lime as $9 \%$ and stone dust as $20 \%$ to the dry weight of the soil, the MDD has been increased to $17.4 \mathrm{kN} / \mathrm{m}^{3}$ and thereafter it decreases for further increments of stone dust. The CBR soil samples are soaked for 72 hours and then it is tested for the untreated condition, the value obtained is $1.50 \%$. The CBR values kept increasing up to $9 \%$ of lime content added to the soil and thereafter it reduces. For an optimum dose of lime content, the CBR value reported as $12.8 \%$. The alteration in the CBR value is found when the soil is mixed with optimum dose of lime and stone dust. At $20 \%$ of stone dust and optimum lime content, the CBR value reported as $22 \%$ and beyond this point, the CBR value gets decreases with further increase in stone dust content. The UCS test is performed on untreated black cotton soil and obtained the value of 166.2 $\mathrm{kN} / \mathrm{m}^{2}$. The behaviour of black cotton soil with lime content is studied and from the test results, it could be concluded that for $9 \%$ of lime content in the soil attains maximum UCS value of $169 \mathrm{kN} / \mathrm{m}^{2}$. Further, the increment of stone dust had also influenced the UCS values to increase but only up to $20 \%$ of stone dust mix proportion, and at this proportion UCS value is reported as $182 \mathrm{kN} / \mathrm{m}^{2}$ and thereafter it decreases. To study the reaction between the soil particles with stone dust and lime, X-ray diffraction analysis is also performed. From this analysis, it is evident to conclude that the formation of ettringite had taken place, which can reduce the tendency of swelling of soil and improves the soil strength. SEM images prove that there is good bonding between the soil particles at optimum lime content and $20 \%$ of stone dust [4].

\subsubsection{Findings}

X-ray diffraction analysis discloses that the formation of ettringite had taken place in the soil after utilizing the stone dust and lime. Ettringite can reduce the tendency of swelling of soil and improves the soil strength. Optimum dose of stone dust and lime is $20 \%$ and $9 \%$.

\subsubsection{Summary}

Stone dust is produced during the manufacturing of fine aggregate and it is not at all suitable to use as a construction aggregate in any of the civil engineering works hence there is a need to dispose of this effectively. Therefore it is adopted as a stabilizer to increase shear resistance in expansive soils.

\subsection{Rice rusk ash and fly ash}

The comparisons of fly ash and rice husk ash as a stabilizer to the black cotton soil have been studied [5]. The black cotton soil was procured from Raipur of Chhattisgarh state. Rice hush ash (RHA) is obtained from open clay brick kiln at Sarona village of Raipur district and the fly ash (FA) is procured from nearby thermal power station of same district. Rice husk ash is used in different percentage ranging from $3 \%$ to $15 \%$ at an interval of $3 \%$ to the dry weight of the soil and the fly ash is used in the range of $5 \%, 8 \%, 10 \%, 12 \%$ and $15 \%$ to the dry weight of the soil. Laboratory experiments such as Atterberg's limits, maximum dry density (MDD) and optimum moisture content (OMC), California bearing ratio (CBR) and unconfined compressive strength (UCS) tests were performed on the origin soil and stabilized soil as well. The black cotton soil used in this work contains blackish grey clayey silt with intermediate plasticity. The black cotton soil used in this study belongs to CI-MI classification according to Indian code and based on AASHTO classification; it is categorized as A-7-5 (4). The liquid limit and plastic limit of black cotton soil is $47 \%$ and $30 \%$. Basic 
geotechnical properties on rice husk ash and fly ash is also conducted, the liquid limit of rice hush ash is $94 \%$ and the liquid limit of fly ash is $84 \%$. Both the rice husk ash and fly ash are considered to be non-plastic. The effect of RHA and FA on the specific gravity values have been studied individually. The untreated black cotton soil has the specific gravity of 2.63, as the RHA stabilizer is increased the specific gravity values tend to decrease. The specific gravity value at $15 \%$ of RHA content to black cotton soil reported as 2.43 . The effect of FA on the specific gravity values of stabilized soil also follows same pattern, at $15 \%$ of FA the specific gravity is 2.45 . This concludes that neither the RHA content nor the FA content will increase the specific gravity value of black cotton soil. The effect of RHA and FA on the plasticity index values has been studied. Unstabilized black cotton soil has the plasticity index value of $17 \%$. Due to increase in the RHA content to the soil, the plasticity index values starts to descend. The plasticity index at $15 \%$ of RHA to the soil reported as $6 \%$. When soil is mixed with FA, much changes is not observed in the plasticity index value up to $8 \%$ of FA but beyond this content there is slight decrease in the graph. However, at $15 \%$ of FA the plasticity index value is $14 \%$. Although there is decrease in the plasticity index values for FA content mixed to soil, it is not at all comparable to the effect of RHA content used. The virgin black cotton soil had the MDD of $18.6 \mathrm{kN} / \mathrm{m}^{3}$ at $\mathrm{OMC}$ of $11.9 \%$. Soil mixed with higher percentage of RHA showed decrease in the MDD values mean while the OMC kept increasing. With $15 \%$ of RHA content in soil the MDD decreased to $17.2 \mathrm{kN} / \mathrm{m}^{3}$ and OMC reported as $19 \%$. It is noted that when FA is added to the soil, there is drastic decrease in the MDD values and mean while slight increase in the OMC values, the MDD obtained at $15 \%$ of $\mathrm{FA}$ is $13 \mathrm{kN} / \mathrm{m}^{3}$ at $\mathrm{OMC}$ of $12 \%$. Both the stabilizers do not provide sufficient increase in the dry density values to the black cotton soil. CBR soil specimens are prepared for the desired moisture content obtained from MDD and OMC test, later it is soaked for 96 hours according to IS guidelines. The soaked CBR value of untreated black cotton soil is $9.2 \%$. Addition of RHA to the black cotton soil had shown appreciable increase in the CBR value up to $11 \%$ of the RHA content and once it surpasses this content, the CBR value tends to decrease. The maximum CBR value reported at $11 \%$ of RHA content is $12 \%$ and at $15 \%$ addition of RHA the value reduces to $8.9 \%$, which is higher enough to the raw black cotton soil. Intrusion of FA to the black cotton soil had also shown similar trend when it is compared with RHA content. The CBR is marked highest at $12 \%$ of FA content as $11.5 \%$ and at $15 \%$ of FA, the CBR decreases to $8 \%$. Looking at the CBR values, it is evident that irrespective of stabilizer agent such as RHA or FA, the soaked CBR value is expected to increase up to $11 \%$ to $12 \%$ of stabilizer agent to the soil. UCS value of raw sample is $118 \mathrm{kN} / \mathrm{m}^{2}$, when the soil is stabilized with RHA content, the UCS value registered as $170 \mathrm{kN} / \mathrm{m}^{2}$ at $9 \%$ of RHA content and it seems to be the highest later it tends to decrease for further contents of RHA to the soil. But the trend line for FA is different, that is use of FA to the soil registered the highest value of $350 \mathrm{kN} / \mathrm{m}^{2}$ at $12 \%$ of FA content. Based on the results obtained, FA as stabilizer agent proves to be right choice for improvement of UCS values thereby soil with FA as stabilizer will have good shear resistance capacity compared to RHA content; with this it is possible to conclude the optimum dosage of RHA and FA as $9 \%$ and $12 \%$ to the dry weight of the soil. Cost analysis is also carried out for $1 \mathrm{KM}$ of road length and it is observed that use of RHA and FA had significantly reduced the cost by $14 \%$ and $20 \%$ to the total cost of road construction [5].

\subsubsection{Findings}

The maximum dry density has increased with the addition of rice hush ash to the soil leading to a reduction in optimum moisture content. But the addition of fly ash results in a decrease in the maximum dry density. The optimum dose of fly ash is $12 \%$ and of rice husk ash is $9 \%$.

\subsubsection{Summary}

Fly ash is the product obtained due to the burning of coal and this waste contains few ingredients which are found in the cement. Hence it becomes a very cost-effective product to stabilize the expansive soil and it will also enhance the binding property of soil particles. Rice husk ash is the agricultural byproduct obtained from rice mill which contains 15$20 \%$ of silica.

\subsection{Coir fiber and coir pith}

Marine clays form one of the key groups of fine grained soils. Stacks of civil construction activities take place in such marine clays throughout the world. The marine clays are highly compressive and of low shear strength. The properties of saturated marine soil differ considerably from moist soil and dry soil. The shrinkage characteristics of expansive soil stabilized with coir waste material is studied [6]. Clay soil is procured from Cochin marine basin from a depth of $1 \mathrm{~m}$. The soil is powdered to a size less than $4.75 \mathrm{~mm}$ and it is sun dried to reduce the moisture content in the soil to $0 \%$. The coir waste is procured from Sasthamkotta, Kollam district, Kerala. Coir waste is also sun dried to bring moisture content to $0 \%$. Since the coir waste contains small fibers and coir waste in them, therefore two category of coir material is used, one being coir fiber which is retained on $4.75 \mathrm{~mm}$ sieve and other being coir pith or coir waste which passes $4.75 \mathrm{~mm}$ sieve. The laboratory experiments are conducted by varying coir pith content in the range of $0 \%$ to $3 \%$ at an increment of $0.5 \%$ and coir fiber content ranging from $0 \%$ to $1 \%$ at an interval of $0.2 \%$ of dry weight of soil. The clay soil belongs to $\mathrm{CH}$ classification with liquid limit of 59\%, plastic limit of $26 \%$ and shrinkage limit of $15 \%$. The 
work mainly concentrates on shrinkage behaviour of soil mixed with coir fiber and coir waste. Shrinkage indices are computed based on IS code and ASTM provisions. The untreated clay soil had MDD of 1.35 g/cc and OMC of $26 \%$. The variations of Atterberg's limits, plasticity index and shrinkage index with coir pith content are studied. From the test results, it is evident that the liquid limit, plastic limit and shrinkage limit values tend to be increasing with increase in coir pith content. The shrinkage index tends to decrease gradually as the coir pith content is increased. However, the plasticity index does not revealed any changes in its value at different mix dose of coir pith. The effect of coir pith on shrinkage strain values is studied. Shrinkage strains in linear and diametric direction were first calculated and were used to determine volumetric shrinkage strains. From the test results, it is observed that the volumetric shrinkage have reduced from $75 \%$ to $60 \%$ and linear shrinkage values have declined from $50 \%$ to $25 \%$ but in diametric directions the shrinkage does not change with the addition of coir pith. Further when soil is treated with coir fiber, the liquid limit and plastic limit values does not change much but trend in the shrinkage limit values kept increasing with increase in coir fiber content. Due to the addition of coir fiber, the shrinkage index and plasticity values tend to decrease slightly with increment in coir fiber content. The effect of coir fiber to shrinkage strain is not much differing compared to coir pith condition. From the test results, it is evident that volumetric shrinkage had reduced from $72 \%$ to $61 \%$ and linear shrinkage values had declined from $48 \%$ to $22 \%$ but in diametric direction the shrinkage does not change with addition of coir fiber [6].

\subsubsection{Findings}

Three-dimensional shrinkage tests are preferred to calculate the shrinkage index. An increase in the coir pith results increase in the consistency limits, an increase in the liquid limit due to the addition of coir pith leads to the formation of clay platelets into coarser aggregates. The optimum dose of coir fiber and coir pith is $1 \%$ and $3 \%$.

\subsubsection{Summary}

Coir fiber and waste is an environmental friendly waste accumulating radically in coir manufacturing countries. Because of its tensile load carrying capacity and strength, it has been used to stabilize the expansive soil also to improve the overall potential of the soil.

\subsection{Jute}

Jute fiber as a soil reinforcement material is one of the most economic and multipurpose natural fibers. The strength parameters of fiber reinforced expansive soil using jute by varying fiber content and fiber length have been studied [7]. The jute fiber is used in the range varying from $0 \%$ to $0.9 \%$ at an increment of $0.3 \%$ to the weight of soil and three different lengths of fiber is used they are $6 \mathrm{~mm}, 12 \mathrm{~mm}$ and $18 \mathrm{~mm}$. Expansive soil is procured from Shanghai and it is identified as fine grained clay soil after conducting grain sieve analysis. Laboratory experiments such as direct shear test and consolidated-undrained (CU) triaxial compression test are conducted to study the effect of fiber added to the soil in terms of fiber content and fiber length. Direct shear test is conducted for all soil specimens using four vertical pressures varying from $100 \mathrm{kPa}$ to $400 \mathrm{kPa}$. Shear strength versus vertical stress plot is prepared for all vertical pressures by varying fiber content in the soil. Untreated soil had $172 \mathrm{kPa}$ of shear strength when loaded with $100 \mathrm{kPa}$ of vertical pressure. From the test results, it is evident that the soil mixed with $0.6 \%$ of fiber content had resulted $240 \mathrm{kPa}$ of shear strength at $400 \mathrm{kPa}$ vertical pressure. All other fiber contents produce good shear strength but they are not comparable to $0.6 \%$ of fiber content added. The behaviour of treated soil to cohesion is studied with respect the different fiber content added. It is observed that, the cohesion value increase for all percentages of fiber content added irrespective of fiber length. However, $12 \mathrm{~mm}$ length of fiber performed well during the test resulting highest cohesion value of $129 \mathrm{kPa}$ at $0.6 \%$ of fiber content to that of $85 \mathrm{kPa}$ of untreated soil. Beyond $0.6 \%$ to the soil, the cohesion value declines considerably irrespective of fiber lengths. Angle of internal friction of untreated soil is reported as $25.5^{0}$. At $0.3 \%$ of fiber content and $6 \mathrm{~mm}$ length fiber to soil, the angle of internal friction is reported as $26^{0}$, which is considered to be highest value among all the fiber content added and this value starts to decrease beyond $0.3 \%$ of fiber content. But for $0.6 \%$ of fiber content and $12 \mathrm{~mm}$ length fiber to soil, the angle of internal friction is also $26^{0}$ and the value starts to decrease beyond this fiber content. $18 \mathrm{~mm}$ fiber length did not perform well in gaining higher internal friction angle for all fiber contents added. In order determine the effects of fiber content and length, soil moisture and dry density, consolidated-undrained (CU) triaxial compression test is conducted. Since water content play major role in the shear strength parameters, effect of water content on response of fiber content is studied (soil density 1.80 g/cc and fiber length of $12 \mathrm{~mm}$ ). Increase in water content resulted increase in the cohesion value up to 18\% of moisture content for all percentages of fiber content added. However, beyond $18 \%$ of moisture content the cohesion values tend to decrease. For all fiber content added, internal friction angle values declined gradually during the addition of moisture content to the soil [7]. 


\subsubsection{Findings}

Use of jute fiber results in the higher density of soil mass leading to the strength influencing mechanism. Higher density requires high compaction energy and this has reduced plastic deformation of soil particles which are in contact with the fiber. The most effective jute fiber content in expansive soil is $0.6 \%$ and a length of $6 \mathrm{~mm}$.

\subsubsection{Summary}

Jute fiber is considered as a gold fiber which is one of the best inexpensive and multipurpose fibers used in treating problematic soils. The study revealed that the use of jute fiber in expansive soil will lead to an increase in the internal friction angle. Thus it will benefit in improving the bearing capacity of the soil.

\subsection{Bagasse ash and ground granulated blast furnace slag}

The engineering properties of black cotton soil (BC) treated with combination of bagasse ash (BA) and ground granulated blast furnace slag (GGBS) is studied [8]. Black cotton soil is procured from Dahej near Bharuch region, Gujarat state, India. GGBS is procured from Jindal Steels, Bellary. Firstly, BA is varied from $6 \%$ to $15 \%$ at an increment of $3 \%$ by keeping GGBS as 10\% constant to the black cotton soil. Secondly, with BA content from 6\% to $15 \%$ at an increment of 3\% the GGBS content is kept constant as $15 \%$ to the soil. The procured BC soil is air dried and basic properties are determined. The BC soil belongs to CL classification as per IS code provisions. The Atterberg's limits for untreated BC soil are as follows; liquid limit of $63.79 \%$, plastic limit of $25.48 \%$ and shrinkage limit of $14.05 \%$. Laboratory experiments such as maximum dry density (MDD) \& optimum moisture content (OMC), unconfined compression strength test (UCS) and California bearing ratio (CBR) are performed to know the combination effects of industrial wastes used. The use of BA and GGBS in the soil results in decrease in liquid limit and plasticity index values. Untreated black cotton soil had MDD of $17.34 \mathrm{kN} / \mathrm{m}^{3}$ with OMC of $14.4 \%$. Use of $9 \%$ of BA and $15 \%$ of GGBS reported MDD of $19 \mathrm{kN} / \mathrm{m}^{3}$ and OMC of $12 \%$. As the BA content is increased irrespective of GGBS content, the MDD values tend to decrease and OMC increases. The virgin BC soil has UCS value of $82.92 \mathrm{kN} / \mathrm{m}^{2}$ and this value got increased to $280 \mathrm{kN} / \mathrm{m}^{2}$ at $12 \%$ of BA content and $15 \%$ of GGBS content, thereafter it decreases to further increments of BA. The CBR value of origin BC soil is $2.05 \%$ and this value got increased to $5.5 \%$ at $12 \%$ of BA content and $15 \%$ of GGBS content, thereafter it decreases to further increments of BA [8].

\subsubsection{Findings}

The optimum dosage of bagasse ash and ground granulated blast furnace slag is $10 \%$ and $15 \%$ to have extreme effects on black cotton soil.

\section{8,2 Summary}

The bagasse ash and GGBS has contributed more towards the strength gain of the expansive soil. Some of the properties in GGBS hold nearly to the fly ash and this is already being recognized as a partial replacing product to cement. Thus it makes an effective material to be used in the expansive soil. On the other hand, the bagasse ash is normally disposed of in the landfill, which has led to severe environmental issues hence it is used as a stabilizer material to treat expansive soil.

\section{Conclusion}

An attempt is made to review various stabilizing materials used to improve the geotechnical properties of expansive soil. It can be concluded that the use of materials discussed above was already recognized as a stabilizer to improve the soil strength. Each and individual material have made their mark on the expansive soil. However, one should be careful enough in selecting the stabilizing material keeping in mind that the cost consideration, availability of the material near the site, and trained labours to work with it. Also, a thorough investigation has to be done to evaluate their reliability in field applications. Long term durability tests have to be conducted on the expansive soils with these stabilizers to know their resistance against adverse loading and atmospheric conditions. Much emphasis should be given to microstructural analysis to understand bonding between the soil particles and stabilizers and for waste reuse.

\section{References}

[1] Vijay Rajoria, Suneet Kaur (2015) “Effect of polymer stabilizer on the geotechnical properties of black cotton soil”, 50th Indian Geotechnical Conference.

[2] Nadgouda K.A., Hegde R.A. (2010) “The Effect of Lime Stabilization on Properties of Black Cotton Soil”, Indian Geotechnical Conference, pp. 511-514. 
[3] Sabat Akshaya Kumar, Pati Subasis, Mohapatro B.G. (2010) "Effect of Fiber on Properties of Rice Husk Ash-Lime Stabilized Soil”, Indian Geotechnical Conference, pp. 373-376.

[4] Ankur Mudgal, Raju Sarkar, A.K.Sahu (2014) "Effect of lime and stone dust in the geotechnical properties of black cotton soil”, Int.J.of GEOMATE, Vol. 7, pp. 1033-1039.

[5] Laxmikant Yadu, Rajesh Kumar Tripathi, Dharamveer Singh (2011) "Comparison of Fly Ash and Rice Husk Ash Stabilized Black Cotton Soil”, International Journal of Earth Sciences and Engineering, Vol. 4, pp. 42-45.

[6] P.K.Jayasree, Balan K., Leema Peter, Nisha K.K. (2015) "Shrinkage Characteristics of Expansive Soil Treated with Coir Waste", Indian Geotech J, pp. 360-367, https://doi.org/10.1007/s40098-015-0144-8.

[7] Wang Yixian, Guo Panpan, Shan Shengbiao, Yuan Haiping, Yuan Binxiang (2016) "Study on Strength Influence Mechanism of Fiber-Reinforced Expansive Soil Using Jute”, Geotech Geol Eng, DOI 10.1007/s10706-016-0028-4.

[8] Sejal P.Dalal, Riddhi Patel, Dalal P.D. (2016) "Effect on Engineering Properties of Black Cotton Soil treated with Agricultural and Industrial waste”, International Conference on Recent Trends in Engineering and Material Sciences, pp. 9640-9644.

[9] Leema Peter, P.K.Jayasree, Balan K., Alaka Raj S. (2014) "Laboratory Investigation In The Improvement Of Subgrade Characteristics Of Expansive Soil Stabilised With Coir Waste", 11th Transportation Planning and Implementation Methodologies for Developing Countries, pp. 558-566.

[10] Erdal Cokca, Veysel Yazici, Vehbi Ozaydin (2008) "Stabilization of Expansive Clays Using Granulated Blast Furnace Slag (GBFS) and GBFS-Cement”, Geotech Geol Eng, DOI 10.1007/s10706-008-9250-z.

[11] Anil Pandey, Ahsan Rabbani (2017) "Soil Stabilisation using Cement”, International Journal of Civil Engineering and Technology, Vol. 8, pp. 316-322.

[12] Leonardo Behak (2017) “Soil Stabilization with Rice Husk Ash”, IntechOpen, DOI: 10.5772/66311

[13] Arpitha I.V.Gowda, Guruprasada M.D., Manoj S., Manu S., Nagaraj K., Goutham D.R. (2019) "Experimental Investigation on Expansive Soil Stabilized Using Bagasse Ash”, International Journal of Innovative Research in Science, Engineering and Technology, Vol. 8, pp. 6728-6733.

[14] Anjan Patel (2019) “Geotechnical Investigations and Improvement of Ground Conditions”, Woodhead Publishing, https://doi.org/10.1016/C2018-0-01307-9.

[15] Sukrit Garg, Veena U., (2016) “Analysis of Strength Properties of Sandy Soil stabilized with Sugarcane Bagasse Ash”, International Journal of Engineering Research \& Technology, Vol. 5, pp. 767-769.

[16] G.L.Shivkumar Babu, A.K.Vasudevan, M.K.Sayida (2008) "Use of Coir Fibers for Improving the Engineering Properties of Expansive Soils”, Journal of Natural Fibers, http://dx.doi.org/10.1080/15440470801901522.

[17] Soosan T.G., Sridharan A., Jose B.T., Abraham B.M. (2005) "Utilization of quarry dust to improve the geotechnical properties of soils in highway construction”, Geotech Test J., https://doi.org/10.1520/GTJ11768.

[18] Chijioke Christopher Ikeagwuani, Donald Chimobi Nwonu (2019) "Emerging trends in expansive soil stabilization: A review", Journal of Rock Mechanics and Geotechnical Engineering, https://doi.org/10.1016/j.jrmge.2018.08.013.

[19] Habiba Afrin (2017) “A Review on Different Types Soil Stabilization Techniques”, International Journal of Transportation Engineering and Technology, Vol. 3, pp. 19-24.

[20] Aghileh Khajeh, Reza Jamshidi Chenari, Meghdad Payan (2019) "A Simple Review of Cemented Non-conventional Materials: Soil Composites”, Geotech Geol Eng, https://doi.org/10.1007/s10706-019-01090-x.

[21] Fazal E.Jalal , Yongfu Xu , Babak Jamhiri , Shazim Ali Memon (2020) “On the Recent Trends in Expansive Soil Stabilization Using Calcium-Based Stabilizer Materials (CSMs): A Comprehensive Review”, Advances in Materials Science and Engineering, https://doi.org/10.1155/2020/1510969.

[22] Aref al Swaidani, Ibrahim Hammoud, Ayman Meziab (2016) "Effect of adding natural pozzolana on geotechnical properties of lime-stabilized clayey soil”, Journal of Rock Mechanics and Geotechnical Engineering, http://dx.doi.org/10.1016/j.jrmge.2016.04.002.

[23] Dina A.Emarah, Safwat A.Seleem (2017) “Swelling soils treatment using lime and sea water for roads construction”, Alexandria Engineering Journal, http://dx.doi.org/10.1016/j.aej.2017.08.009. 


\section{Authors' Profiles}

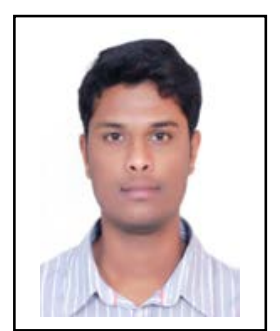

Goutham D.R. received his B.E., in Civil Engineering and M.Tech., in Computer Aided Design of Structures (CADS) from Visvesvaraya Technological University, Belagavi, India. He is working as Assistant Professor in the Department of Civil Engineering, Adichunchanagiri Institute of Technology, Chikkamagaluru, India. Also he pursuing Ph.D., under Dr.A.J.Krishnaiah, Professor and Head, Department of Civil Engineering, Malnad College of Engineering, Hassan affiliated to Visvesvaraya Technological University, Belagavi, India. His research interest is soil stabilization and soil-structure interaction.

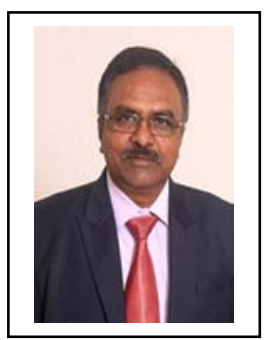

Dr.A.J.Krishnaiah received his B.E., in Civil Engineering and Master of Science Engineering (By Research) from the University of Mysore. He also received his Ph.D., for the thesis titled "Strength and Compressibility Behaviour of Compacted Fine Grained Expansive and Non Expansive Soils in Presence of Mine Tailings and other Additives” from Bangalore University, Bengaluru, India. He is currently working as Professor and Head, Department of Civil Engineering, Malnad College of Engineering (MCE), Hassan, India. His research interest is soil stabilization and soil-structure interaction.

How to cite this paper: Goutham D.R., A.J.Krishnaiah, " Improvement In Geotechnical Properties Of Expansive Soil Using Various Stabilizers: A Review ", International Journal of Engineering and Manufacturing (IJEM), Vol.10, No.5, pp.18-27, 2020. DOI: 10.5815/ijem.2020.05.02 